\title{
ANALISIS INTERCARRIER INTERFERENCE (ICI) SISTEM OFDM-MIMO STBC PADA KANAL FREQUENCY SELECTIVE FADING
}

\author{
I Wayan Diki Andriasmika ${ }^{1}$, I.G.A.K. Diafari Djuni H ${ }^{2}$, N.M.A.E. Dewi Wirastuti ${ }^{3}$ \\ ${ }^{123}$ Program Studi Teknik Elektro, Fakultas Teknik, Universitas Udayana \\ Email: dikiandriasmika@gmail.com ${ }^{1}$, igakdiafari@unud.ac.id ${ }^{2}$, dewi.wirastuti@unud.ac.id ${ }^{3}$
}

\begin{abstract}
ABSTRAK
Telekomunikasi wireless menuntut akses dengan kecepatan tinggi. Salah satu teknik yang digunakan untuk mengatasi multipath fading adalah Ortoghonal Frequency Division Multiplexing (OFDM). Kelemahan OFDM terjadi pada kanal mobile yang disebabkan variasi waktu pada kanal sehingga menimbulkan intercarrier interference (ICI).Penelitian bertujuan mengetahui pengaruh normalized carrier frequency offset terhadap ICl dan pengaruh tap kanal frequency selective fading. Hasil simulasi menunjukkan performansi sistem pada perhitungan nilai Eb/NO $5 \mathrm{~dB}$ bahwa semakin besar normalized carrier frequency offset $(\epsilon)$ maka sinyal semakin buruk. Hasil simulasi menunjukkan performansi sistem OFDM-MIMO pada perhitungan nilai Eb/NO $5 d B$ bahwa semakin besar lintasan (tap) pada kanal maka sinyal semakin buruk.

Kata Kunci: BER, Intercarrier Interference (ICI), OFDM-MIMO, Tap Kanal Frequency Selective Fading.

\section{ABSTRACT}

Wireless telecommunications requires high-speed access. One technique used to overcome multipath fading is Ortoghonal Frequency Division Multiplexing (OFDM). The weakness of OFDM occurs on the mobile channel due to time variations in the channel, giving rise to intercarrier interference (ICI). The aim of the study is to determine the effect of normalized carrier frequency offset on $\mathrm{ICl}$ and the effect of frequency selective fading tap channel. The simulation results show the system performance in calculating the Eb / NO $5 \mathrm{~dB}$ value that the greater the normalized carrier frequency offset $(\epsilon)$, the worse the signal. The simulation results show the OFDM-MIMO system performance in calculating the Eb / NO $5 \mathrm{~dB}$ value that the greater the tap on the channel the worse the signal.
\end{abstract}

Keywords: BER, Intercarrier Interference (ICI), OFDM-MIMO, Frequency Selective Fading Tap Channel.

\section{PENDAHULUAN}

Perkembangan telekomunikasi digital, pada komunikasi wireless menuntut akses kecepatan yang melebihi sebelumnnya dengan syarat tahan dengan interferensi. Penggunaan bandwidth pada sisi penerima dan pemancar dengan skema STBC Almouti sebagai teknik pendeteksi yang digabungkan dengan sistem Multiple Input Multiple Output (MIMO) dan salah satu teknik yang digunakan untuk meminimalisir multipath fading adalah Ortoghonal Frequency Division Multiplexing (OFDM). [1]. Perubahan kanal pada OFDM yang semula bersifat frekuensi selective fading akan berubah seperti kanal flat fading oleh beberapa subcarrier [2]. Tetapi OFDMMIMO memiliki kelemahan, yaitu sulitnya sinkronisasi dan sensitive pada pergeseran frekuensi (frequency offset) antara pemancar dan penerima yang disebabkan oleh pengaruh kanal [2]. Efek dari frequency offset adalah sifat orthogonal dari sub-carrier akan hilang dan akan menyebabkan pergeseran frekuensi (ICI). Penelitian ini akan menganalisa kinerja suatu sistem komunikasi wireless dengan menggabungkan penggunaan teknik OFDM-MIMO dengan menerapkan skema STBC Alamouti. Penelitian tentang STBC sudah dilakukan pada D-MIMO dengan menggunakan teknik waterfilling [3]. Dengan menggunakan teknik tersebut dapat mengetahui pengaruh normalized carrier frequency offset $(\epsilon)$ terhadap InterCarrier Interference (ICl) dengan modulasi 
QPSK dan pengaruh tap pada kanal frequency selective fading.

\section{KAJIAN PUSTAKA}

\subsection{Ortoghonal Frequency Division} Multiplexing (OFDM)

OFDM adalah teknik modulasi menggunakan beberapa frekuensi carrier (multicarrier). Masing-masing sub-carrier diwajibkan saling orthogonal dan tidak menyinggung satu sama lain, sehingga antara sub-carrier dapat dibuat tumpeng tindih tanpa menimbulkan efek inte-rcarrier interference ( $\mathrm{ICl}$ ) yang ditunjukkan pada Gambar 1 (b). Pada teknik modulasi konvensional FDM, suatu bandwidth tertentu dibagi menjadi beberapa kanal tersendiri berdasarkan frekuensi dengan diberi jarak antar kanal yang ditunjukkan pada Gambar 1 (a) [8].

Gambar 1 Prinsip (a) FDM dan (b) OFDM [8] Syarat dua sinyal dikatakan orthogonal dapat dilihat pada Persamaan 1 [8].

$$
\int_{0}^{T} \cos \left(2 \pi f_{1} t+\emptyset\right) \cos \left(2 \pi f_{2} t\right) d t=0 \ldots(1)
$$

Dengan mengintegralkan persamaan 1, maka [8] :

$$
\cos \emptyset=\left[\frac{\sin \left(2 \pi\left(f_{1}-f_{2}\right)\right) T}{2 \pi\left(f_{1}-f\right)}\right] \sin \varnothing\left[\frac{\sin \left(2 \pi\left(f_{1}-f_{2}\right)\right) T-1}{2 \pi\left(f_{1}-f_{2}\right)}\right] .
$$

Jadi dapat dijelaskan bahwa jika beda fasa antar dua sinyal tidak dapat diketahui sehingga kedua sinyal tersebut harus berbeda frekuensi 1/T agar orthogonal.[8].

2.2 Multiple Input and Multiple Output (MIMO)

Dalam telekomunikasi gelombang radio, MIMO yaitu metode untuk menggandakan kapasitas coverage melalui banyak antena untuk memancarkan dan menerima data. MIMO menggunakan beberapa antena transmitter dan receiver untuk menyempurnakan kinerja sistemnya yang ditunjukkan pada Gambar 2. MIMO merupakan teknik yang melalui beberapa antena untuk secara koheren mengurai lebih banyak informasi dibanding menggunakan antenna tunggal [4].

\subsection{Teknik STBC}

Gambar 2 Antena MIMO [4]

Skema tramsisi STBC merupakan skema transmisi yang ditemukan oleh Siavash Alamouti di tahun 1998. STBC adalah skema yang dipergunakan dalam teknik untuk memperbaiki diversity gain pada sistem MIMO tersebut. Alur data yang sama dipancarkan melalui kedua antena pemancar. Sebelum dikirimkan, alur data terlebih dahulu mendapatkan perlakuan yang berbeda [4].

\subsection{Carrier Frequency Offset (CFO)}

Pada penerima diwajibkan ada sinkronisasi sebelum demodulasikan subcarrier, diantaranya memperbaiki pergeseran frekuensi atau Carrier Frequency Offset (CFO) sinyal yang diterima akan menyebabkan pergesran frekuensi $(\mathrm{ICl})$.

CFO mempunyai nilai normalized yang ditunjukkan pada persamaan 3 .

$$
\epsilon=\frac{\text { Foffset }}{\Delta f} \text {..... }
$$

dimana nilai normalized CFO adalah besarnya frekuensi akibat pergeseran antenna pemancar dan $\Delta f$ adalah spasi sub-carrier, yaitu nilai dari spasi dari masing-masing sub-carrier paramtere tersebut adalah untuk menentukan gangguan yang disebabkan pergeseran frekuensi. Sinyal OFDM sebelum melintasi kanal ditunjukkan pada Gambar 3 (a) dan sinyal OFDM setelah melintasi kanal ditunjukkan pada Gambar 3 (b) [5].

Gambar 3 Sinyal OFDM: a). Sebelum melewati kanal b). Setelah melewati kanal [6]

\subsection{Kanal Frequency Selective Fading}

Kanal selective fading diakibatkan dari dispersi waktu simbol yang ditransmisikan di kanal. Sehingga kanal mengakibatkan intersymbol interference. Dalam domain frekuensi, frekuensi tertentu adalah komponen pada sinyal yang diterima 
memiliki penguat lebih baik dari yang lain. Kanal selective fading sedikit lebih susah untuk dimodelkan dari kanal flat fading hal itu disebebakan setiap sinyal multipath kanal diasumsikan sebagai filter. Dalam selective fading, sinyal yang dipancarkan mempunyaii bandwidth yang lebar dari bandwidth koheren dari kanal. Kanal menjadi frekuensi selective ketika kuat antena berbeda sehingga komponen frekuensi juga berbeda. Kanal selective fading disebabkan delay yang mendekati atau menjauhi simbol periode dari simbol yang dipancarkan [7].

\section{METODELOGI PENELITIAN}

\subsection{Parameter Simulasi}

Parameter yang digunakan dalam simulasi sistem OFDM dapat dilihat pada Tabel 1 [9].

Tabel 1 Parameter Simulasi

\begin{tabular}{|l|c|}
\hline \multicolumn{1}{|c|}{ Parameter } & Nilai \\
\hline $\begin{array}{l}\text { Panjang simbol } \\
\text { OFDM (L) }\end{array}$ & 64 \\
\hline $\begin{array}{l}\text { Number of used } \\
\text { subcarriers }\end{array}$ & 52 \\
\hline Jumlah simbol FFT & QPSK \\
\hline Tipe modulasi & $20 \mathrm{Mhz}$ \\
\hline $\begin{array}{l}\text { FFT Sampling } \\
\text { Frequency }\end{array}$ & $4 \mathrm{kHz}$ \\
\hline Spasi Sub-carrier & $3.2 \mu \mathrm{s}$ \\
\hline Used subcarrier index & $0.1,+1$ to +26$\}$ \\
\hline Periode FFT & $4 \mu \mathrm{s}$ \\
\hline Periode CP & $1.000 .000\left(10^{6}\right)$ \\
\hline Periode Simbol Total & \\
\hline Bit Generator &
\end{tabular}

\subsection{Pemodelan Sistem OFDM-MIMO}

Pada penelitian ini, diagram alir sistem OFDM-MIMO pada kanal Frequency Selective Fading keseluruhan dapat dilihat pada Gambar 4. . Mulai dari study literature, perangkat keras, perancangan perangkat lunak, dan terakhir adalah proses pengujian dari simulasi yang telah dibuat.

Gambar 4 Diagram Alir Penelitian Umum

\subsection{Alur Penelitian Umum}

Secara umum alur penelitian yang dilakukan terdiri atas beberapa tahap. Tahap pertama membuat pemodelan sistem OFDM- MIMO dengan parameter diambil dari Tabel 1. Dari pemodelan tersebut, dibuatkan script terdiri atas script untuk pemodelan OFDM-MIMO dengan variasi normalized carrier frequency offset dan variasi jumlah tap pada kanal frequency selective fading. Selanjutnya adalah script untuk pemodelan OFDMMIMO dengan jumlah tap pada kanal frequency selective fading yang berbeda. Hasil simulasi berupa grafik dan nilai BER vs. Eb/NO untuk sistem OFDM-MIMO yang mengalami Frequency offset dan yang tidak mengalami Frequency offset. Setiap simulasi yang dilakukan menggunakan nilai Eb/NO yang sama yaitu dari 0 sampai 10 dB. Hasil simulasi sistem OFDM MIMO yang mengalami Frequency offset kemudian dibandingkan dengan hasil dari sistem yang tidak mengalami Frequency offset kemudian dari hasil analisis tersebut didapat simpulan dari penelitian ini yang ditunjukkan pada Gambar 5.

Gambar 5 Diagram Alur Analisis Penelitian Umum

\section{Hasil dan Pembahasan}

4.1 Hasil Pengujian Simulasi

Pengujian sistem berdasarkan parameter tabel 1 yang telah dilakukan menggunakan shoftware MatLab telah mendapatkan hasil grafik dan nilai.

A. Hasil Pengujian Sistem Mengalami Frequency Offset

Gambar 6 berikut ini menunjukkan hasil pengujian sistem yang tidak mengalami frequency offset dan sistem 
yang mengalami frequency offset dengan jumlah bit inputan $10^{6}$, dimana sumbu y pada grafik adalah Bit Error Rate (BER) sedangkan sumbu $x$ adalah Eb/NO. Grafik dengan warna hijau menunjukkan BER kanal AWGN tanpa mengalami frequency offset sedangkan grafik dengan warna biru menunjukkan BER kanal AWGN mengalami frequency offset. Grafik dengan warna merah menunjukkan BER kanal frequency selective fading tanpa mengalami frequency offset sedangkan grafik dengan warna kuning menunjukkan BER kanal frequency selective fading mengalami frequency offset..

Gambar 6 Perbandingan Sistem Tidak Mengalami Frequency Offset Dengan Sistem Yang Mengalami Frequency Offset.

B. Hasil Simulasi Sistem Dengan Nilai Normalized Carrier Frequency Offset (€) Yang Bervariasi.

Gambar 7 berikut ini menunjukkan hasil pengujan sistem dengan nilai $(\epsilon)$ bervariasi dengan jumlah bit inputan $10^{6}$, dimana sumbu y pada grafik adalah Bit Error Rate (BER) sedangkan sumbu $x$ adalah Eb/NO. Grafik dengan warna hijau menunjukkan sistem tanpa ICI, grafik dengan warna merah menunjukkan sistem dengan $\mathrm{ICl}$ ternormalisasi $(\epsilon)=0.5$ berikutnya garfik dengan warna biru menunjukkan sistem dengan $\mathrm{ICl}$ ternormalisasi $(\epsilon)=1$, sedangkan grafik dengan warna merah muda menunjukkan sistem dengan $\mathrm{ICI}$ ternormalisasi $(\epsilon)=1.5$

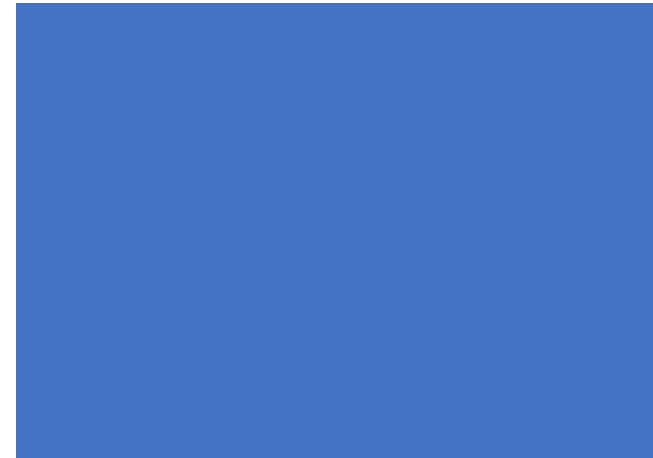

Gambar 7 Perbandingan Sistem dengan nilai normalized carrier frequency offset $(\epsilon) 0.5,1$, dan 1.5.

C. Hasil Pengujian Simulasi Sistem Dengan Jumlah Tap Bervariasi Pada Kanal Frequency Selective Fading

Gambar 8 menunjukkan hasil pengujian sistem dengan jumlah tap (lintasan) bervariasi pada kanal frequency selective fading dengan jumlah bit inputan $10^{6}$, dimana sumbu y pada grafik adalah Bit Error Rate (BER) sedangkan sumbu $x$ adalah Eb/NO. Grafik dengan warna hijau menunjukkan sistem dengan jumlah tap (lintasan) 2, grafik dengan warna merah menunukkan sistem dengan jumlah tap (lintasan) 3, grafik dengan warna biru menunjukkan sistem dengan jumlah tap (lintasan) 5, sedangkan garfik dengan warna merah muda menunjukkan sistem dengan jumlah tap (lintasan) 7 .

Gambar 8 Perbandingan Tap Kanal Frequency Selective Fading pada sistem

\subsection{Pembahasan Hasil Pengujian} Sistem

Berdasarkan pengujian dari sistem tidak terjadi kendala yang menyebabkan kegagalan pada saat simulasi.Namun bukan berarti simulasi sistem tidak memiliki kekurangan.

A. Perbandingan Sistem Yang Tidak Mengalami Frequency Offset 
dengan Sistem Mengalami Frequency Offset.

Hasil dan grafik perbandingan unjuk kerja sistem OFDM-MIMO yang tidak mengalami frequency offset dengan sistem OFDM MIMO yang mengalami frequency offset ditunjukkan pada Gambar 6.

Pada sistem OFDM MIMO yang tidak mengalami frequency offset memiliki nilai BER lebih rendah dikarenakan carrier pada transmitter dan pada receiver mengalami overlapping antar sub-carrier secara tegak lurus (orthogonal) antara satu dengan yang lainnya, sehingga antara sub-carrier tidak terinterfrensi satu sama lain. Sedangkan carrier transmiter dan carrier receiver pada sistem OFDM MIMO yang mengalami frequency offset $2 \mathrm{kHz}$ mengalami ketidaksesuaian karena masing-masing antar sub-carrier mengalami pergeseran sebesar $2 \mathrm{kHz}$ antar sub-carrier sehingga orthogonalitas antar sub-carrier tidak ada lagi karena pergeseran tersebut dan terjadi interfrensi antar carrier atau intercarrier interference $(\mathrm{ICl})$ maka sinyal informasi menjadi lebih buruk, Sehingga dari hal tersebut dapat mempengaruhi pada grafik BER, semakin besar Eb/N0 akan berpengaruh pada nilai BER yang semakin mengecil.

B. Perbandingan Unjuk Kerja Sistem Dengan Nilai Normalized Carrier Frequency Offset (є) Yang Bervariasi.

Unjuk kerja sistem OFDM-MIMO pada kanal frequency selective fading dengan pengaruh nilai normalized carrier frequency offset $(\epsilon)$ yang bervariasi yaitu $0.5,1$, dan 1.5 terhadap Inter-carrier Interference (ICI) dapat ditunjukkan pada Gambar 7.

Semakin besar normalized carrier frekuensi offset $(\epsilon)$ pada sistem maka semakin besar juga nilai frequency offset dan semakin sempit spasi antar sub-carrier, sehingga perbandingan antara frekuensi maksimum dan spasi frekuensi antara subcarrier semakin besar, sehingga semakin besar pula interferensi antar sub-carrier atau inter-carrier interference (ICl) yang mengakibatkan sinyal semakin buruk.

C. Perbandingan Jumlah Tap di Kanal Frequency Selective Fading pada sistem.

Perbandingan Grafik BER vs Eb/NO Tap Kanal Frequency Selective Fading pada sistem OFDM-MIMO ditunjukkan pada Gambar 8.
Semakin besar jumlah lintasan (tap) Frequency Selective Fading pada sistem akan menyebabkan ketidaksesuaian sinyal informasi dari transmitter dan receiver karena data transmisi mengalami perubahan magnitude dan phase pada masing-masing sub-carrier setelah melewati kanal frequency selective fading akibat lintasan pantul yang semakin banyak.

\section{SIMPULAN}

Kinerja sistem OFDM-MIMO yang tidak mengalami frequency offset lebih baik dibandingkan dari sistem OFDM-MIMO yang mengalami frequency offset $2 \mathrm{kHz}$ pada kanal frequency selective fading menggunakan modulasi QPSK. Hasil perbandingan sistem OFDM-MIMO dengan nilai normalized carrier frequency offset $(\epsilon)$ yang berbeda yaitu $0.5,1$ dan 1.5 , diketahui bahwa semakin besar normalized carrier frequency offset $(\epsilon)$ maka sinyal informasi semakin buruk. Hasil perbandingan unjuk kerja sistem OFDM-MIMO dengan tap pada kanal frequency selective fading yang bervariasi Dimana Semakin besar jumlah lintasan (tap) pada kanal frekuensi selective fading maka Eb/NO semakin buruk atau BER akan semakin besar.

\section{DAFTAR PUSTAKA}

$\begin{array}{llr}\text { [1] Wahyudi, Rizky } & \text { Analisis } \\ \text { Penanggulangan Inter } & \text { Carrier } \\ \text { Interference di } & \text { OFDM }\end{array}$ Menggunakan Zero Forcing Equalizer, Bandung, Fakultas Teknik Elektro, Universitas Telkom.2016.Tersedia: https://media.neliti.com/media/publicati ons.telkom/222561-analisis-simulasiperformansi-ICl.pdf Diakses Tanggal 7 Desember 2018.

[2] Xiao, Y. Orthogonal Frequency Division Multiplexing Modulation and Inter-Carrier Interference Cancellation 2003.Tersedia:

https://digitalcommons.lsu.edu/gradsch ool theses/1619/ Diakses Tanggal 7 Desember 2018.

[3] Gunantara, N, "Analisis Unjuk Kerja Teknik Pengkodean STBC dan Waterfilling Pada Sistem D-MIMO". Majalah Ilmiah Teknik Elektro, vol. 7, no. 2, July - December 2008.

[4] Apsari, Eka. Analisis Perbandingan Performansi Sistem MC-SS MIMO 
dengan OFDM MIMO Pada Kanal Fading, Fakultas Teknik Elektro,Universitas Udayana.2017. Tersedia:

https://ojs.unud.ac.id/index.php/JTE/art icle/view/ID21338 Diakses Tanggal 8 Desember 2018.

[5] Suharjo, Bambang. Analisis penanggulangan inter-carrier interference pada Teknologi OFDM Interpolasi Spline dalam MATLAB, Fakultas Teknik Universitas Muhammadiyah Gresik Diliyanzah,Asri,2014. Tersedia:

https://libraryeproceeding.telkomuniver sity.ac.id/index.php/engineering/article/ view/3000 Diakses Tanggal 8 Desember 2018.

[6] Purwanto, Teguh Bayu. "Analisis Unjuk Kerja Teknik MIMO STBC dan V-BLAST Pada Sistem Orthogonal Frequency Division Multiplexing," ST. Skripsi, Denpasar: Universitas Udayana, 2015.Tersedia:

https://ojs.unud.ac.id/index.php/JTE/art icle/view/ID21338 Diakses Tanggal 8 Desember 2018.

[7] Jarot, Sigit Puspito Wigati. "Mengenal Teknologi OFDM pada Komunikasi Wireless 1999.Tersedia:

https://www.elektroindonesia.com/elekt ro/tel24.html Diakses Tanggal 5 Desember 2018.

[8] https:/miqbal.staff.telkomuniversity ac.id/orthogonal-frequency-divisionmultiplexing-ofdm/ Diakses Tanggal 8 Desember 2018.

[9] IEEE 802.11a Specification Standards Association. 1076.3-2009. IEEE Standard VHDL Synthesis Packages. New York: IEEE Press; 2009.Tersedia: http://www.dsplog.com/2008/08/26/ofd m-rayleigh-channel-ber-bpsk/ Diakses Tanggal 9 Desember 2018. 